\title{
Evaluation of stress-strain behavior of surface treated steels by X-ray diffraction
}

Research article

\author{
Luis Coelho $^{1,2}$, A.C. Batista ${ }^{1}$, J.P. Nobre ${ }^{1,3}$, M.J. Marques ${ }^{1,4}$ \\ 1 CEMDRX, Department of Physics, University of Coimbra, P-3004-516, Coimbra, Portugal \\ 2 School of Technology and Management, Polytechnique Institute of Leiria, P-2411-901, Leiria, Portugal \\ 3 Department of Mechanical Engineering, University of Coimbra, P-3030-201 Coimbra, Portugal \\ 4 Department of Physics Engineering, University of Porto, P-4200-465 Porto, Portugal
}

Received 1 July 2011 ; accepted 29 September 2011

\begin{abstract}
X-ray diffraction assisted four-point bending method (XRDABM) enables to analyze the evolution of surface stress with the strain during bending of specimens. This experimental methodology was used to characterize the stressstrain behavior of two plasma nitriding steels, DIN $40 \mathrm{Cr}$ Mn Mo 7 and DIN $32 \mathrm{Cr}$ Mo V 13, with gradients of mechanical properties across the surface layers, allowing the characterization of the in-depth evolution of the local yield strength in the nitrided layer. The results show a significantly increase of the yield strength of the nitride layers and a good agreement between the in-depth evolution of the yield strength and the XRD peak breadth for the two nitrided steels.

Keywords: X-Ray ciffraction • Four-point-bending-method $•$ Nitrided steels $\bullet$ Surface treated layers $\bullet$ Stress-strain behavior $\bullet$ Yield strength

(c) Versita sp. z o.o.
\end{abstract}

\section{Introduction}

The knowledge of the local yield strength and stress-strain behavior of the surface treated steels, due to mechanical, thermal or thermo-chemical surface treatments, such as, e.g., shot-peening, quenching and nitriding, has a great relevance in several areas of mechanical engineering science. For example, to deeply study problems of fatigue, contact fatigue or wear, valid behavior laws for the surface-treated material layers are needed. Since in those damage mechanisms the initial damage occurs, in general, at surface near regions, materials science and surface engineering advise the use of structural ductile steels, having its surface modified by coatings and/or surface treatments [1].
Surface hardening treatments can modify the chemical composition, microstructure and mechanical properties of surface-near material's regions, generating compressive residual stresses in the surface layer, which are beneficial relatively to fatigue damage phenomena. Therefore, the elasto-plastic behavior of the material near the surface should be completely different from that found for the bulk material. The particular nature of these hardened layers, which do not exist independently and are subjected to residual stresses, does not allow the determination of their mechanical properties by the classical mechanical tests, due to the difficulty of obtaining samples with a homogeneous cross-section, representative of those layers. Several techniques have been proposed for evaluating the mechanical properties of materials' surfaces [2-10], beyond 
the traditional microhardness data and X-ray diffraction peak width analysis, which qualitatively show the hardening or softening of the material's surface layers [11]. In fact, $X$-rays analysis enables to study the in-depth variation of diffraction peak width. This value is related to the square root of the mean quadratic value of the distortion of the crystalline lattice $\left\langle\varepsilon^{2}\right\rangle^{1 / 2}$, which is directly proportional to the microscopic residual stress ( $3^{\text {rd }}$ order stresses) [12]. It was observed that the dislocation density varies in depth according to the variation of X-ray diffraction peak width, i.e., the higher the diffraction peak width, the higher the dislocation density [13]. It means that X-ray diffraction peak width quantify the strain hardening attained by the surface material. Micro-hardness measurements made along the cross-section of surface-treated specimens are an similarly efficient way of characterizing the mechanical behavior of their surface layers, since hardness is a direct measure of the material's strength and can be related to its yield strength [8].

The method used in this work is a important and practical application of X-rays analysis in this knowledge area [2]. The local yield strength throughout the affected nitrided layer was determined for two steels subjected to different nitriding surface treatments. Local yield strength values significantly increases from the bulk material till the nitrided surface and a good agreement between the in-depth evolution of the yield strength and the XRD peak width for the two nitride steels was observed.

\section{Description of the method (XRD- ABM)}

In the X-ray diffraction assisted by four-point bending method (XRDABM) the surface treated specimens are subjected to monotonic bending using a purpose-built device [2]. Before the specimen is loaded, the initial residual stress state at specimen's surface is determined by the XRD $\sin ^{2} \Psi$ method [14]. The specimen is then subjected to successive strain increments. For each strain increment, controlled by the electric strain gages attached to the material's surface, the corresponding stress is determined by XRD. As X-rays only penetrate the material slightly, the determined stresses are characteristics of the specimen's surface. However, the stress determined by XRD corresponds to the sum of the applied bending stress and the residual stress imposed by the nitriding treatment. In addition, the strain determined by the strain gages depends only on the applied bending stress. Therefore, the measured strains, $\varepsilon_{\text {measured }}$, have to be corrected to take into account the initial elastic strain, $\varepsilon_{R}$ (being $\varepsilon_{R}=\frac{\sigma^{R S}}{E}$ ), i.e., the strain corresponding to the existing residual stresses

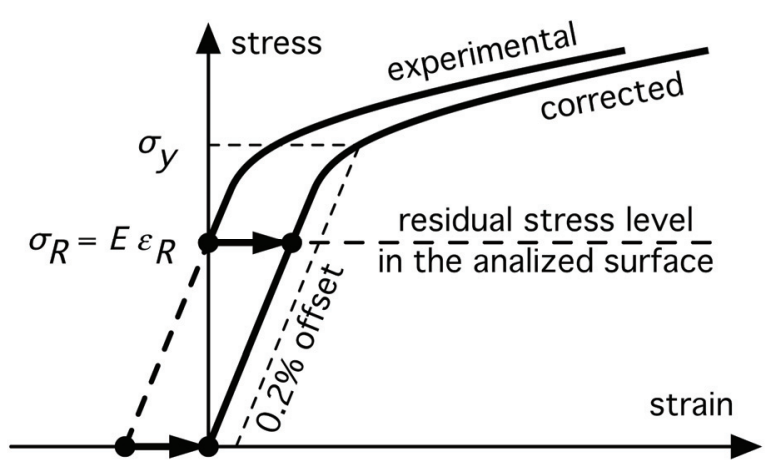

Figure 1. Correction of the stress-strain curve due to the presence of residual stresses and $0.2 \%$ offset yield strength $\left(\sigma_{y}\right)$ determination.

at the specimen's surface (Fig. 1). This correction can be made by using the following equation, where $E$ is the Young's modulus:

$$
\varepsilon_{\text {corrected }}=\varepsilon_{\text {measured }}+\frac{\sigma^{R S}}{E} .
$$

It is therefore possible to determine a characteristic stressstrain curve for the treated material at the specimen's surface, enabling the local yield strength determination (Fig. 1). The in-depth evolution of the local yield strength can be determined after removing the upper layers with a non hardening procedure, such as electropolishing. In this case, for each evaluated depth, one specimen has to be used.

\section{Materials and Experimental Pro- cedure}

The nitride steels used in this work exhibit important properties, particularly in terms of hardness, hot hardness, high toughness, contact fatigue life, wear and corrosion endurance. These sets of characteristics make it mainly suitable for severe application conditions, namely, aeronautic bearings [15], helicopter transmission gears [16], manufacturing parts submitted to important efforts $[17,18]$. These properties are difficult to obtain so appropriate and reliable metallurgical solutions must be found. The choice of deep nitriding for high load and elevated temperature applications, instead of the carburizing process, can be justified by economical reasons and superior structural stability of the nitriding layer when heated [19]. As the plasma nitriding treatment is performed at relatively low temperature, the parts suffer little deformation during the process. Another advantage is the possibility to preserve a good toughness of the bulk steel, which allows its ap- 


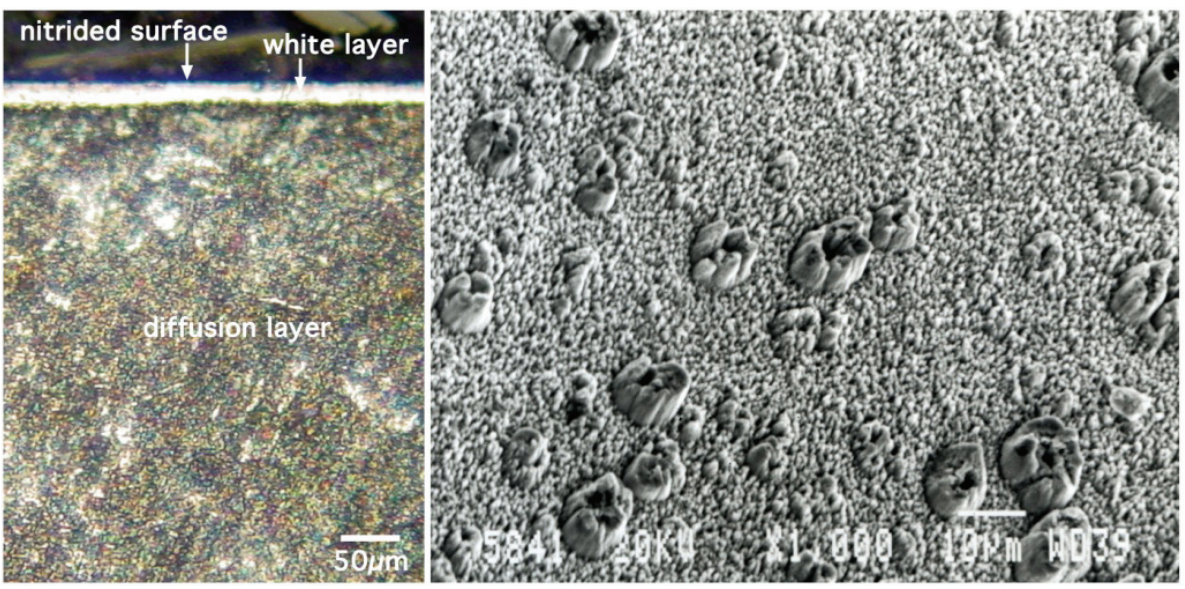

Figure 2. Optical micrograph of cross-section (left) and SEM micrograph of the white layer surface (right), of DIN 32 Cr Mo V 13 plasma nitrided steel.

Table 1. Chemical composition of the nitrided steels.

\begin{tabular}{lccccccc}
\hline \multirow{2}{*}{ Steel } & \multicolumn{6}{c}{ Chemical composition [\% weight] } \\
\cline { 2 - 8 } & $\mathrm{C}$ & $\mathrm{Si}$ & $\mathrm{Mn}$ & $\mathrm{Ni}$ & $\mathrm{Cr}$ & Mo & V \\
\hline \hline DIN 32 Cr Mo V 13 & 0.32 & 0.35 & 0.52 & 0.14 & 3.0 & 0.83 & 0.28 \\
DIN 40 Cr Mn Mo 7 & 0.4 & - & 1.5 & - & 1.9 & 0.2 & - \\
\hline
\end{tabular}

plication in high rotation velocities. The nitrided steels employed in this work are shown in Table 1.

Fig. 2 left presents a characteristic optical micrograph of the cross-section of the nitrided specimens. DIN $32 \mathrm{Cr} \mathrm{Mo}$ $\checkmark 13$ nitrided steel presents a white layer with a thickness of $18 \mu \mathrm{m}$, and a diffusion zone with about $380 \mu \mathrm{m}$ depth. The microstructure of the treated surface, obtained by scanning electronic microscope (SEM), is shown in Fig. 2 right. The DIN $40 \mathrm{Cr}$ Mn Mo 7 nitrided steel presents a microstructure similar to that shown in Fig. 2. In this case, however, the thickness of its white layer is lower and equal to $15 \mu \mathrm{m}$, while the thickness of its diffusion zone is lower and equal to $150 \mu \mathrm{m}$, respectively, when compared to the DIN 32 Cr Mo V 13 nitrided steel layers. In both cases, according to the $\mathrm{X}$-ray diffraction results, the white layer presents, mainly, $\gamma^{\prime}\left(\mathrm{Fe}_{4} \mathrm{~N}\right)$ and only traces of nitrides $\varepsilon\left(\mathrm{Fe}_{2-3} \mathrm{~N}\right)$ and the diffusion layer is formed by nitride precipitates in a nitrogen solid solution.

\section{X-ray diffraction analysis}

Stress determination was performed with a PROTO iXRD portable with Flexible Fiber Optics PSSD Detectors (Position Sensitive Scintillation Detector) (Fig. 3). Lattice deformations of the $\{211\}$ diffraction planes of the $\alpha-\mathrm{Fe}$ phase were measured using $\mathrm{Cr} \mathrm{K} \alpha \mathrm{X}$-ray radiation, using

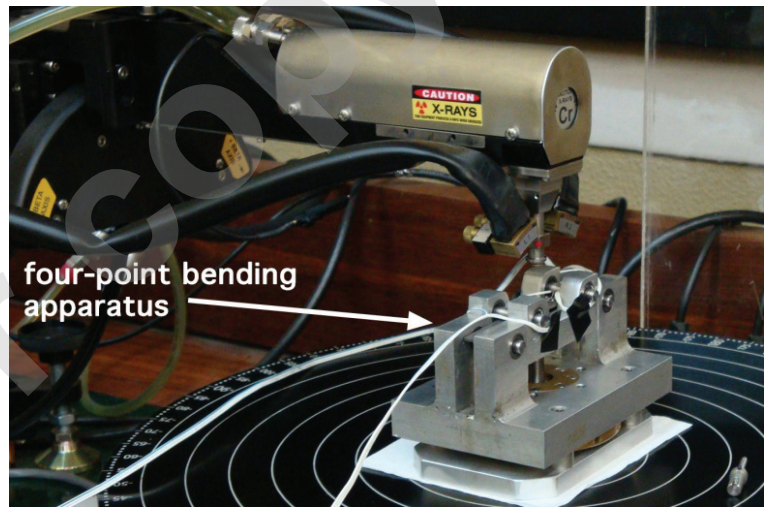

Figure 3. Proto iXRD and four point bending device.

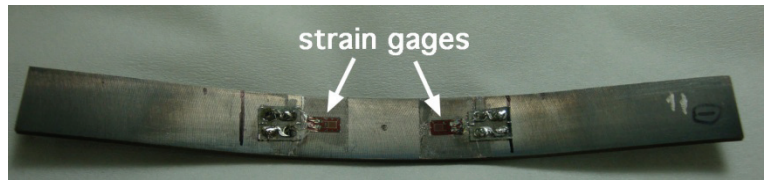

Figure 4. Four point bending sample after compression test.

a goniometer. The stress was evaluated in the longitudinal direction of the samples, using $22 \Psi$ angles, an acquisition time of 30 seconds by peak and $\pm 2^{\circ}$ oscillation in $\Psi$. For the materials analyzed and considering the radiation used, the average penetration of the X-rays is about $5 \mu \mathrm{m}$. The strain in the surface of the samples was measured with Kyowa electric resistance strain gages, type KFG-2-120C1-11 (Fig. 4), which can be used to measure strains up to about $5 \%$, according to the producer specifications. 


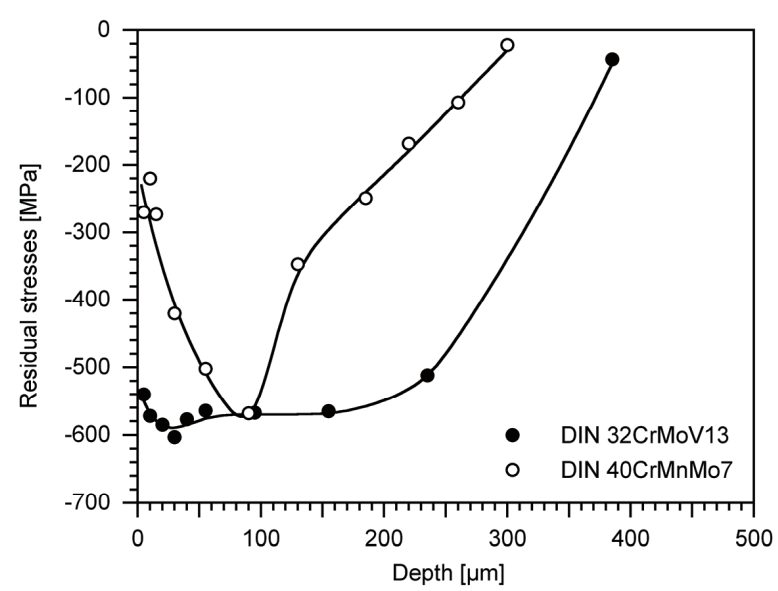

Figure 5. In-depth residual stress profile in the nitrided steels.

\section{Results and discussion}

In-depth residual stress profiles obtained by XRD in the two nitrided steels are shown in Fig. 5. A constant residual stress value of about $-550 \mathrm{MPa}$ in the first $200 \mu \mathrm{m}$ is observed in DIN $32 \mathrm{Cr}$ Mo V 13 nitrided steel, followed by a decrease of the compressive stresses up to a depth of $400 \mu \mathrm{m}$. The nitriding treatment of the DIN $40 \mathrm{Cr}$ Mn Mo 7 steel develops compressive residual stresses which reach a maximum value of $-600 \mathrm{MPa}$, at a depth of $90 \mu \mathrm{m}$, followed by a small decrease. The compressive residual stress affects a total thickness of $300 \mu \mathrm{m}$.

The XRDABM method was used to determine the local yield strength $(0.2 \%$ offset yield strength) in the nitrided surfaces, intermediate layers and bulk materials of the two nitrided steels. Fig. 6 and Fig. 7 show the obtained in-depth evolution of the local yield strength and the diffraction peak width, for both nitrided steels. According to the X-ray diffraction peak width profile, the thickness of the nitrided layer is about $150 \mu \mathrm{m}$ and $380 \mu \mathrm{m}$, for DIN 40 Cr Mn Mo 7 and DIN 32 Cr Mo V 13 steels, respectively. It is clear that local yield stress and diffraction peak width variation showed the same behavior. As diffraction peak width increases, local yield stress also increases and vice-versa. Nobre et al. [8] also observed the same behaviour. In DIN $40 \mathrm{Cr}$ Mn Mo 7 nitrided steel (Fig. 6), maximum yield stress seems to occur close to the material's surface ( $2400 \mathrm{MPa})$. This value decreases continuously in the surface layers affected by the nitriding treatment till the value found for the bulk material is attained ( $700 \mathrm{MPa})$. For deeper layers, local yield stress do not varies significantly. In the case of DIN 32 Cr Mo V 13 steel (Fig. 7), however, yield stress increases in the layers close to the surface ( 1000 MPa), attaining a maximum value ( $2300 \mathrm{MPa})$ for a depth equal to

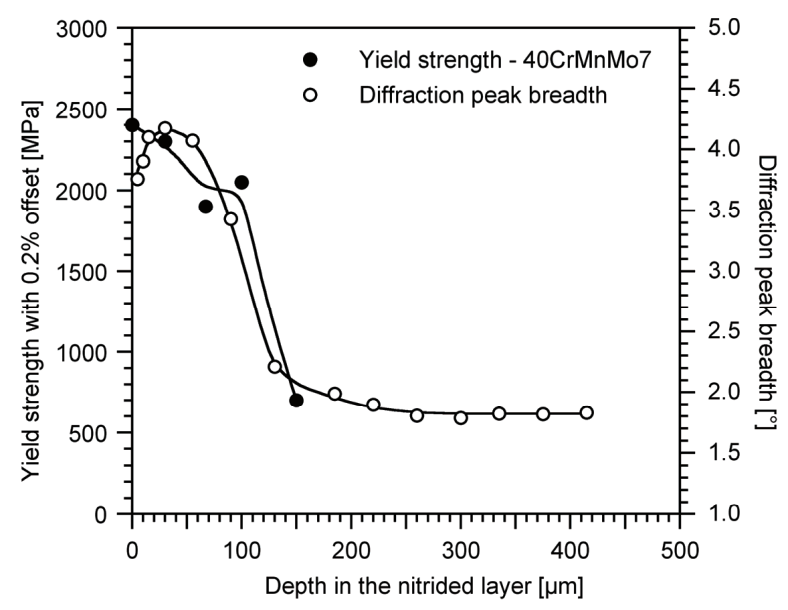

Figure 6. In-depth yield strength and X-ray diffraction peak breadth in the DIN $40 \mathrm{Cr}$ Mn Mo 7 steel.

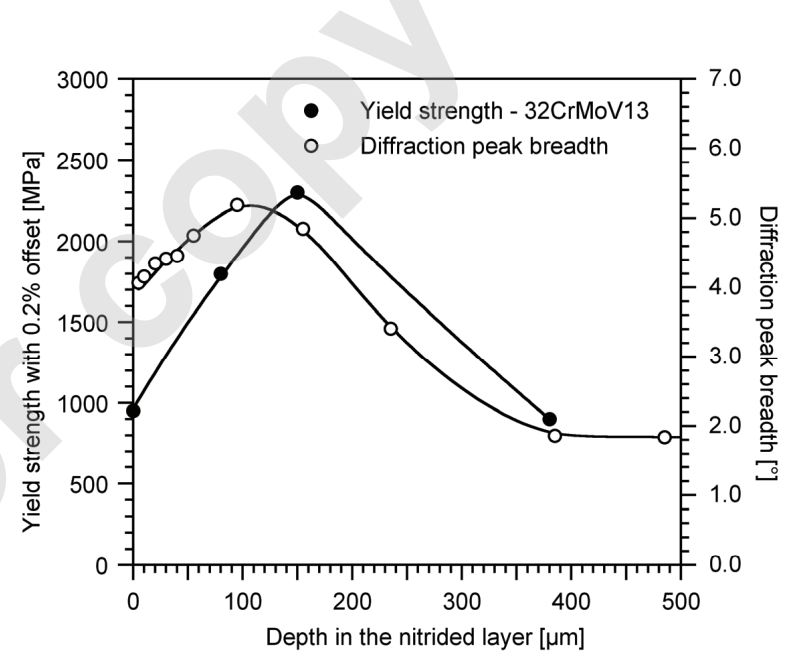

Figure 7. In-depth yield strength and X-ray diffraction peak breadth in the DIN $32 \mathrm{Cr}$ Mo V 13 steel.

$150 \mu \mathrm{m}$ approximately, after decreasing continuously and attained the bulk material value ( 900 MPa). The application of the XRDABM methodology point out that the yield strength vs depth is different for both nitrided steels, showing clearly the differences between the two nitriding treatment conditions.

\section{Conclusions}

The XRDABM method has been applied to DIN $40 \mathrm{Cr}$ Mn Mo 7 and DIN 32 Cr Mo V 13 nitrided steels, with different nitriding depths and residual stress distributions, allowing the determination of the local yield strength across the treated layer. 
The results showed an increase of the yield strength in the nitride layers comparatively to the bulk material. A good agreement between the in-depth yield strength and the XRD peak breadth in the two steels was observed.

The application of the XRDABM method point out that the yield strength vs depth is different for both nitrided steels. This difference should be related to the different parameters used during the two nitriding treatments.

\section{Acknowledgments}

The authors acknowledge the financial support of the European Union program FEDER through "Programa Operacional Factores de Competitividade - COMPETE" and of the Portuguese Government through "FCT - Fundação para a Ciência e a Tecnologia" under the project with reference PEst-C/FIS/UI0036/2011.

\section{References}

[1] Devi M.U., Mohanty O.N., Plasma-nitriding of tool steels for combined percussive impact and rolling fatigue wear applications. Surf. Coating Tech., 1998. 107: 55-64

[2] Batista A.C., Dias A.M., Characterization of Mechanical Properties in Surface-Treated Materials, J. Test. Eval., 2000. 28(3): 217-223

[3] Virmoux P., Inglebert G., Gras R., Characterisation of Elasto-Plastic Bheaviour for Contact Purposes on Surface Hardened Materials. Dissipative Processes in Tribology, 1994. D. Downson et al. eds., Elsevier Science B.V.,: 287-301

[4] Guechichi H., Castex L., Fatigue Limits Predition of Surface Treated Materials. J. Mater. Process. Tech., 2006. 3(172): 381-387

[5] Cao W., Castex L., Determination of Stress-Strain Relation of the Shot Peened Surface Layers with the help of X-Ray Diffraction Half-Width, in Metal Behaviour and Surface Engineering, B. Curioni, B. Waterhouse, and D. Kirk, Editors. 1989, IITT-International, 309-314

[6] Cao Y.P., Lu J., A new method to extract the plastic properties of metal materials from an instrumented spherical indentation loading curve, Acta Mater., 2004. 52: 4023-4032

[7] Giannakopoulos A.E., Suresh S., Determination of elastoplastic properties by instrumented sharp indentation, Scripta Mater., 1999. 40(10): 1191-1198
[8] Nobre J.P., Dias A.M., Kornmeier M., An Empirical Methodology to Estimate a Local Yield Stress in Workhardened Surface Layers, Exp. Mech., 2004. 44(1): 76-86

[9] Nobre J.P., Batista A.C., Coelho L., Dias A.M., Two experimental methods to determining stress-strain behavior of work-hardened surface layers of metallic components, J. Mater. Process. Tech., 2010. 210: 22852291

[10] Elghazal H., Hamel A., Girodin D., Vincent A., Microplasticity characteristics obtained through nanoindentation measurements: application to surface hardened steels, Mater. Sci. Eng., 2001. A303: 110119

[11] Scholtes B., Eigenspannungen in Mechanisch Randschichtverformten Werkstoffzuständen Ursachen, Ermittlung und Bewertung, 1991, Oberursel: Deutsche Gesellschaft fur Materialkunde - DGM Informationsgesellschaft $\mathrm{mbH}$

[12] François M., et al., X-ray Diffraction Method, in Handbook of Measurement of Residual Stresses, J. Lu, Editor. 1996, SEM: Bethel. 71-131

[13] Guechichi H., Prévision des Contraintes Résiduelles dues au Grenaillage de Précontrainte. 1986, ENSAM: Paris

[14] Macherauch E., Müller P., Das sin $\psi$-Verfahren der Röntgenographischen Spannungsmessung, Z. .Angew. Phys., 1961. 13: 305-312

[15] Pichard I., Girodin D., Dudragne G., Moraux J.Y., Metallurgical and Tribological Evaluation of $32 \mathrm{CrMoV} 13$ Nitrided Steel and XD15NTM High Nitrogen Martensitic Stainless Steel for Aerospace Applications, in ASTM STP, J.J.C. Hoo, Editor. 1997

[16] Barralis J., Chaize J.C., Caractérisation des Couches Nitrurés pour Engrenages en 32CDV13 en Vue d'une Amelioration de leur Comportement en Service, Traitement Thermique, 1985. 197: 59-65

[17] Barrallier L., Barralis J., Étude Metallurgique de la Nitruration de l'Acier de Nuance 32CDV13, in Internationaux de France du Traitement Thermique, P. edition, Editor. 1991. 349-351

[18] Chala A., Chekour L., Nouveau C., Saied C., et al., Study of the duplex treatment on 32CrMoV13 low alloy steel: application in wood machining, Surf. Coating Tech., 2005. 200: 512-516

[19] Peyre J.-P., Tournier C., Choix des Traitments Thermiques Superficiels, in Collection Materiaux en Mécanique, P. CETIM, Editor. 1975, CETIM: Paris 